\title{
Pre-Gestational Diabetes and Pregnancy Outcomes
}

\author{
Dalal S. Ali · Recie Davern · Eimear Rutter • Ciara Coveney • \\ Hilary Devine $\cdot$ Jennifer M. Walsh · Mary Higgins $•$ Mensud Hatunic
}

Received: June 11, 2020 / Accepted: September 15, 2020 / Published online: October 3, 2020

(C) The Author(s) 2020

\begin{abstract}
Introduction: Pre-gestational, type 1 and type 2 diabetes are associated with adverse neonatal outcomes and increased rates of emergency caesarean sections.

Methods: We studied pregnancy outcomes associated with pre-gestational diabetes in 174 women who attended the National Maternity Hospital in Dublin, Ireland, between 2015 and 2017.

Results: Fifty women (28.6\%) had type 2 diabetes mellitus, and 124 women $(71.4 \%)$ had type 1 diabetes mellitus. Women with type 2 diabetes mellitus were older (36 vs. 34 years, p 0.02) and had a higher BMI (32.6 vs. $26.2 \mathrm{~kg} /$
\end{abstract}

Digital Features To view digital features for this article go to https://doi.org/10.6084/m9.figshare.12827369.

D. S. Ali · R. Davern · H. Devine · M. Hatunic ( $\square)$ Endocrinology Department, Mater Misericordiae University Hospital, Dublin, Ireland e-mail:mhatunic@mater.ie

D. S. Ali · R. Davern · E. Rutter · C. Coveney · H. Devine · J. M. Walsh · M. Higgins · M. Hatunic The National Maternity Hospital, Holles Street, Dublin, Ireland

R. Davern · H. Devine · J. M. Walsh · M. Higgins . M. Hatunic

University College Dublin, Dublin, Ireland $\mathrm{m}^{2}, p$ 0.00). Duration of diabetes mellitus in type 1 and type 2 was 15.7 and 5.7 years, respectively, and mean HbA1c in type 2 diabetes mellitus at booking was $44.5 \mathrm{mmol} / \mathrm{mol}$ $(6.2 \%)$ and in type 1 diabetes mellitus was $56.3 \mathrm{mmol} / \mathrm{mol}$ (7.3\%). Forty women (32\%) with type 1 diabetes mellitus used continuous subcutaneous insulin infusion. In our cohort, $45.4 \%$ had a caesarean delivery. Offspring of patients with multiple dose injections were lighter $(3.58 \mathrm{~kg})$ than infants of continuous subcutaneous insulin infusion-treated patients $(3.75 \mathrm{~kg})$. More emergency caesarean sections were observed in the continuous subcutaneous insulin infusion group than in the group treated with multiple dose injections $(37.5 \%$ vs. $28.5 \%$ ), while the elective caesarean section rate was higher in the multiple dose injection group $(17.8 \%$ vs. $12.5 \%)$. Women treated with continuous subcutaneous insulin infusion had a higher rate of miscarriage ( $25 \%$ vs. $19 \%)$ with more congenital malformations (10\% vs. $2.3 \%)$. Conclusions: Women in our study with pregestational diabetes were overweight, were older and had long-standing diabetes mellitus. Our patients with type 2 diabetes had a higher BMI, were older, had a shorter duration of diabetes mellitus and had better diabetes control compared to women with type 1 diabetes. Women treated with continuous subcutaneous insulin infusion had a higher rate of miscarriage with more congenital malformations. The initial inadequate diabetes control was 
significantly improved during pregnancy.Keywords: Diabetes; Diabetes in pregnancy; Pregestational pregnancy and diabetes outcomes; Type 1 diabetes; Type 2 diabetes

\section{Key Summary Points}

\section{Why carry out this study?}

Pre-gestational, type 1 and type 2 diabetes are associated with adverse neonatal outcomes.

Previous studies found that adverse maternal outcomes are still high for women with pre-existing diabetes mellitus.

The aim was to study the pre-gestational diabetes impact on pregnancy outcomes in a large maternity hospital with a multidisciplinary team with the intention to improve diabetes in pregnancy outcomes.

\section{What was learned from the study?}

Women with pre-gestational diabetes were overweight and older with long-standing diabetes mellitus; inadequate initial diabetes control significantly improved during pregnancy.

In our study $32 \%$ women with type 1 diabetes were treated with continuous subcutaneous insulin infusion (CSII) in pregnancy.

With an appropriate multidisciplinary team approach, we can minimise adverse outcomes and identified areas for improvement in delivery of care in the future.

\section{DIGITAL FEATURES}

This article is published with digital features to facilitate understanding of the article. To view digital features for this article go tohttps://doi. org/10.6084/m9.figshare.12827369.

\section{INTRODUCTION}

Pre-gestational diabetes mellitus, type 1 diabetes mellitus (T1DM) and type 2 diabetes mellitus (T2DM) are associated with adverse outcomes [1]. Pregnant women with pre-existing diabetes mellitus are at increased risk of congenital malformations $[1,2]$, stillbirth $[1,3,4]$, perinatal mortality $[4,5]$, macrosomia $[1,2,4,6]$, prematurity [4], operative delivery or increased rates of caesarean section (CS) $[1,2,4]$. However, the quality of the care offered to women with diabetes mellitus can affect the adverse birth outcomes [7] in reducing congenital malformations and stillbirths [6]. The level of support during pregnancy improves outcomes in women with diabetes mellitus [8]. Providing appropriate clinical care to women with pre-existing diabetes mellitus has a positive impact on pregnancy outcomes. Previous national and international studies found that adverse maternal outcomes are still high for women with pre-existing diabetes mellitus [6, 9-11]. The goal of the St Vincent Declaration, which was set in 1997, was "achieving pregnancy outcomes in women with diabetes mellitus that approximates that of women with no diabetes mellitus". This declaration has not been accomplished yet [12].

\section{METHODS}

This is a retrospective study of pregnancy outcomes associated with pre-gestational diabetes in women attending the National Maternity Hospital, Dublin, Ireland, over the 3-year period of 2015-2017. The aim of this study was to review the pre-gestational diabetes impact on pregnancy outcomes with the intention to improve diabetes in pregnancy treatment and pregnancy outcomes in a large maternity hospital with a multidisciplinary team. The data were collected from patients' electronic and hard copy medical records. All women had retinal screening at the time of confirmation of 
the pregnancy and in each trimester thereafter. All women with pre-gestation diabetes were treated by a multidisciplinary team including an obstetrician, an endocrinologist, a dietician, a diabetes midwife specialist, an ophthalmologist with 2-3 weekly reviews and weekly phone contacts with diabetes midwives. Miscarriage was defined as spontaneous loss of the foetus before 20 weeks' gestation. Intrauterine foetal death (IUFD) was defined as death that occurred in utero or during delivery at the 20th week of pregnancy or more, or death of the foetus with weight $\geq 500 \mathrm{~g}$ in utero or during delivery. Live births were neonates who survived $\geq 6$ weeks post-delivery. Large for gestational age (LGA) was defined as foetuses measuring $>$ 90th centile and small for gestational age (SGA) defined as $<10$ th centile based on gender-specific hospital growth charts. Pregnancy-induced hypertension (PIH) was defined as systolic blood pressure $(\mathrm{SBP})>140 \mathrm{mmHg}$ and diastolic blood pressure $(\mathrm{DBP})>90 \mathrm{mmHg}$. Pre-eclampsia was defined as new onset hypertension (> $140 \mathrm{mmHg}$ systolic or $>90 \mathrm{mmHg}$ diastolic) after 20 weeks of pregnancy and the coexistence of one or both of the following new-onset conditions: proteinuria (urine protein:creatinine ratio $\geq 30 \mathrm{mg} / \mathrm{mmol}$ or albumin:creatinine ratio $\geq 8 \mathrm{mg} / \mathrm{mmol}$ or $\geq 1 \mathrm{~g} / \mathrm{l}[2+]$ on dipstick testing), other maternal organ dysfunction, including features such as renal or liver involvement, neurological or haematological complications, or uteroplacental dysfunction (such as foetal growth restriction, abnormal umbilical artery Doppler waveform analysis or stillbirth). Congenital anomalies were defined as birth defects that exist at birth and have a possible impact on the health, development and/or survival of the infants [13]. Assisted delivery was defined as using tools (forceps, vacuum) to help deliver the foetus vaginally. Neonatal hypoglycaemia was defined as capillary blood glucose of $<2.6 \mathrm{mmol} / \mathrm{l}$. Near normal maternal HbA1c ( $48 \mathrm{mmol} / \mathrm{mol} / 6.5 \%)$ was described as target A1c in our cohort at their booking visit [14-17]. The data collection for this study was approved by the Research Ethics Committee National Maternity Hospital, Holles Street, Dublin, Ireland. Statistical analysis was performed using the Statistical Package for the Social Sciences, version 26.0 for Windows (IBM SPSS, USA). Continuous variables with normal distribution were presented as mean, standard deviation and median; however, categorical data were presented as frequencies. For binary outcomes, the proportions between groups were compared using chisquare and Fisher's exact tests.

\section{RESULTS}

A total of 174 pregnancies with pre-gestational diabetes mellitus were included in the study (Table 1); 124 (71.4\%) women had T1DM and the remaining $50(28.6 \%)$ had T2DM. Women with T2DM were older ( 36 vs. 34 years, $p 0.02$ ), had a higher BMI (32.6 vs. $\left.26.2 \mathrm{~kg} / \mathrm{m}^{2}, p 0.00\right)$ and had a shorter duration of diabetes mellitus (5.5 vs. 15.7 years, $p$ 0.00) compared to women with T1DM. Most of the women studied in our population were multiparous (58\%). The majority of women with T1DM were of European descent (96\%), whereas the group with T2DM had a higher percentage of non-white ethnic patients (41\%) ( $p$ 0.00). Most of the nonEuropean women were of Asian, Middle Eastern and South American descents. Women with T1DM had a higher documented rate of retinopathy ( $43 \%$ vs. $11 \%, p$ 0.008). Hypothyroidism was also found in both groups but more common in women with type 1 diabetes mellitus $(21 \%$ vs. $17 \%)$.

Pre-pregnancy structured clinics was more common in the T1DM group $(n=49,62 \%)$. The majority of women with T2DM were treated with metformin and multiple daily injections (MDIs) throughout their pregnancy (44\%); however, $20 \%$ used metformin alone and 28\% were on insulin therapy alone. In the group of women with T1DM, $67 \%$ were on MDI and $32 \%$ were treated with continuous subcutaneous insulin infusion CSII throughout their pregnancies.

Labour and foetal outcomes in our cohort (Table 2) showed that 79 (45.4\%) women had a caesarean section (CS) delivery, 40 (24.3\%) had normal vaginal delivery and $13(7.4 \%)$ required assisted vaginal delivery; 36 (20.6\%) pregnancies unfortunately ended with miscarriage. 
Table 1 Maternal baseline characteristics

\begin{tabular}{|c|c|c|c|c|}
\hline Mean $\pm S D$ & $\begin{array}{l}\text { All patients } \\
n=174\end{array}$ & $\begin{array}{l}\text { Type } 1 \text { diabetes } \\
n=124(71.4)\end{array}$ & $\begin{array}{l}\text { Type } 2 \text { diabetes } \\
n=50(28.6)\end{array}$ & $P$ value \\
\hline Age (years) & $34.2 \pm 4.5$ & $33.8 \pm 4.7$ & $35.5 \pm 3.8$ & 0.020 \\
\hline Booking BMI $\left(\mathrm{kg} / \mathrm{m}^{2}\right)$ & $28.3 \pm 6.6$ & $26.2 \pm 4.5$ & $32.6 \pm 8.1$ & 0.000 \\
\hline Duration of diabetes (years) & $12.7 \pm 8.6$ & $15.7 \pm 8.0$ & $5.49 \pm 4.4$ & 0.000 \\
\hline Booking Gestational age (weeks) & $6.7 \pm 3.0$ & $6.0 \pm 1.7$ & $7.8 \pm 4.4$ & 0.190 \\
\hline \multicolumn{5}{|l|}{ Percentage (\%) } \\
\hline European origin & 85.7 & 96.0 & 59.0 & 0.000 \\
\hline \multicolumn{5}{|l|}{ Yes $(n=149)$} \\
\hline Primiparous & 42.0 & 44.0 & 36.0 & 0.384 \\
\hline \multicolumn{5}{|l|}{ Yes $(n=69)$} \\
\hline Pre-conception clinic attendee & 57.2 & 62.0 & 46.0 & 0.117 \\
\hline \multicolumn{5}{|l|}{ Yes $(n=67)$} \\
\hline Preconception folic acid (5 mg) & 68.3 & 70.0 & 64.0 & 0.530 \\
\hline \multicolumn{5}{|l|}{ Yes $(n=80)$} \\
\hline Hypothyroidism & 20.0 & 21.0 & 17.0 & 0.672 \\
\hline \multicolumn{5}{|l|}{ Yes $(n=34)$} \\
\hline \multicolumn{5}{|l|}{ Diabetes complications } \\
\hline Retinopathy & 36.1 & 43.0 & 11.0 & 0.008 \\
\hline \multicolumn{5}{|l|}{ Yes $(n=31)$} \\
\hline \multicolumn{5}{|l|}{ Pregnancy treatment } \\
\hline Metformin & 5.7 & - & 20.0 & \\
\hline \multicolumn{5}{|l|}{ Yes $(n=10)$} \\
\hline MDI & 56.3 & 67.0 & 28.0 & \\
\hline \multicolumn{5}{|l|}{ Yes $(n=98)$} \\
\hline CSII & 23.0 & 32.0 & - & \\
\hline \multicolumn{5}{|l|}{ Yes $(n=40)$} \\
\hline $\mathrm{MDI}+$ metformin & 12.5 & - & 44.0 & \\
\hline \multicolumn{5}{|l|}{ Yes $(n=22)$} \\
\hline Diet only & 0.5 & - & 2 & \\
\hline Yes $(n=1)$ & & & & \\
\hline
\end{tabular}

Data are presented as mean \pm standard deviation $(\mathrm{SD})$ or $\%$

$B M I$ body mass index, MDI multiple daily injections, CSII continuous subcutaneous insulin infusion 
Table 2 Delivery and neonatal outcomes

\begin{tabular}{|c|c|c|c|c|}
\hline Mean \pm SD & $\begin{array}{l}\text { All patients } \\
n=174\end{array}$ & $\begin{array}{l}\text { Type } 1 \text { diabetes } \\
n=124(71)\end{array}$ & $\begin{array}{l}\text { Type } 2 \text { diabetes } \\
n=50(29)\end{array}$ & $P$ value \\
\hline Birth weight (kg) & $3.6 \pm 0.72$ & $3.6 \pm 0.76$ & $3.5 \pm 0.6$ & 0.260 \\
\hline Mode of delivery & \multicolumn{4}{|l|}{ Percentage (\%) } \\
\hline Spontaneous vaginal delivery & 24.3 & 23.4 & 26.0 & 0.549 \\
\hline \multicolumn{5}{|l|}{ Yes $(n=40)$} \\
\hline Elective CS & 17.2 & 16.0 & 20.0 & 0.508 \\
\hline \multicolumn{5}{|l|}{ Yes $(n=30)$} \\
\hline Emergency CS & 28.1 & 32.0 & 18.0 & 0.092 \\
\hline \multicolumn{5}{|l|}{ Yes $(n=49)$} \\
\hline Assisted normal delivery & 7.4 & 7.2 & 8.1 & 0.760 \\
\hline \multicolumn{5}{|l|}{ Yes $(n=13)$} \\
\hline Miscarriage & 20.6 & 20.8 & 18.3 & 0.835 \\
\hline \multicolumn{5}{|l|}{ Yes $(n=36)$} \\
\hline Intrauterine foetal death & 3.4 & 2.4 & 8.1 & 0.099 \\
\hline \multicolumn{5}{|l|}{ Yes $(n=6)$} \\
\hline Live births & 76.5 & 77.6 & 74.0 & 0.268 \\
\hline \multicolumn{5}{|l|}{ Yes $(n=134)$} \\
\hline \multicolumn{5}{|l|}{ Foetal complications } \\
\hline Postnatal hypoglycaemia & 27.4 & 31.3 & 19.3 & 0.331 \\
\hline \multicolumn{5}{|l|}{ Yes $(n=27)$} \\
\hline NICU admission & 45.9 & 52.2 & 32.0 & 0.082 \\
\hline \multicolumn{5}{|l|}{ Yes $(n=45)$} \\
\hline Abdominal circumference $>95$ th & 19.4 & 23.8 & 6.8 & 0.058 \\
\hline \multicolumn{5}{|l|}{ Yes $(n=22)$} \\
\hline Birth weight $>4.5 \mathrm{~kg}$ & 5.2 & 7.2 & - & 0.189 \\
\hline \multicolumn{5}{|l|}{ Yes $(n=7)$} \\
\hline Birth weight $>4.0 \mathrm{~kg}$ & 23.1 & 20.6 & 30.0 & 0.263 \\
\hline \multicolumn{5}{|l|}{ Yes $(n=31)$} \\
\hline Congenital anomalies & 5.3 & 6.3 & 2.7 & 0.675 \\
\hline Yes $(n=7)$ & & & & \\
\hline
\end{tabular}


Table 2 continued

\begin{tabular}{llll}
\hline Mean \pm SD & $\begin{array}{l}\text { All patients } \\
n=\mathbf{1 7 4}\end{array}$ & $\begin{array}{l}\text { Type 1 diabetes } \\
n=\mathbf{1 2 4}(\mathbf{7 1})\end{array}$ & $\begin{array}{l}\text { Type 2 diabetes } \\
\boldsymbol{n}=\mathbf{5 0}(\mathbf{2 9})\end{array}$ \\
\hline $\begin{array}{l}\text { Maternal complications } \\
\text { Pre-eclampsia }\end{array}$ & 9.2 & 10.5 & \\
Yes $(n=13)$ & & & 0.414 \\
Pregnancy-induced hypertension & 19.2 & 21.4 & 13.5 \\
Yes $(n=26)$ & & & 0.340 \\
\hline
\end{tabular}

Data are presented as mean \pm standard deviation (SD) or \%

$B M I$ body mass index, $M D I$ multiple daily injections, $C S I I$ continuous subcutaneous insulin infusion

There were six (3.4\%) recorded cases of intrauterine foetal death, most of which occurred in women with type 2 diabetes mellitus compared to type 1 diabetes mellitus ( $8.1 \%$ vs. $2.4 \%, p 0.099)$. The rate of pre-eclampsia was nearly double in T1DM compared to T2DM patients $(10.5 \%$ vs. $5.4 \%)$. One-fifth of women studied had pregnancy-induced hypertension (19.2\%). There were 134 (76.5\%) live births recorded. Offspring of women with T1DM were more likely to be admitted to the neonatal intensive care unit (NICU) $(52 \%$ vs. $32 \%$, $p$ 0.082) and more likely to get postnatal hypoglycaemia (31\% vs. $19 \%$ ) compared to the offspring of T2DM women. The mean birth weight in the T1DM groups was similar to that in the T2DM group, which was about $3.6 \mathrm{~kg}$. The sonographic appearance of the abdominal circumference of $>95$ th percentiles was nearly four fold higher in the infants of the T1DM cohort $(23.8 \%$ vs. $6.8 \%, p$ 0.058). Congenital anomalies were higher among the T1DM cohort (6.3\% vs. $2.7 \%)$. Overall, $23.1 \%(31, n=134)$ of our studied infants were large for gestational age (LGA) $(>4 \mathrm{~kg})$. Seven $(5.2 \%)$ offspring of T1DM patients weighed $>4.5 \mathrm{~kg}$, whereas no offspring weighed $>4.5 \mathrm{~kg}$ in T2DM. Glycaemic control among our studied population is summarised in Table 3. Women with T2DM had better glycaemic control at the booking visit compared to those with T1DM (HbA1c $45 \mathrm{mmol} / \mathrm{mol}(6.2 \%)$ vs. $56 \mathrm{mmol} / \mathrm{mol}(7.3 \%)$, $p$ 0.04). More than half of women with T2DM had HbA1c at target on their first visit $(52.2 \%$ vs. $16.9 \%, p 0.00$ ). Diabetes control was better in both groups in the second and third trimesters of pregnancy; however, the HBA1c level was significantly lower in the T2DM cohort compared to the T1DM group $(p=0.005$ and $p=$ 0.002 , respectively).

The baseline characteristics of the women with T1DM only are summarised in Table 4. Our cohort treated with CSII had a longer duration of diabetes mellitus compared to those with MDI (18.5 years vs. 14 years, $p=0.015$ ) and had earlier pregnancy bookings ( 5.3 weeks gestation vs. 6.6 weeks, $p=0.024$ ). Most women with T1DM attended pre-pregnancy clinics and had been taking folic acid $5 \mathrm{mg}$ daily prior to conception, $62 \%$ and $71 \%$, respectively. Hypothyroidism was observed more frequently in the CSII group (33\% vs. $15 \%, p=0.07)$.

Maternal and foetal outcomes in T1DM women are summarised in Table 4. Offspring of women with MDI treatment were lighter $(3.58 \mathrm{~kg})$ than infants of CSII-treated women $(3.75 \mathrm{~kg})$. Only $4.4 \%$ of infants in the MDI group had weight $>4.5 \mathrm{~kg}(4.4 \%)$, while $13.7 \%$ of infants of mothers on CSII had weight $>4.5 \mathrm{~kg}$. More emergency CSs were observed in the CSII group $(37.5 \%$ vs. $28.5 \%)$, while the elective CS rate was higher in the MDI group $(17.8 \%$ vs. $12.5 \%)$. Women treated with CSII had a higher rate of miscarriage ( $25 \%$ vs. $19 \%)$ 
Table 3 Glycaemic outcomes and diabetes

\begin{tabular}{|c|c|c|c|c|c|}
\hline & $\begin{array}{l}\text { Type } 1 \text { diabetes } \\
n=124(71)\end{array}$ & $\begin{array}{l}\text { CSII } \\
n=40(32)\end{array}$ & $\begin{array}{l}\text { MDI } \\
n=84(67)\end{array}$ & $\begin{array}{l}\text { Type } 2 \text { diabetes } \\
n=50(29)\end{array}$ & $P$ value \\
\hline \multicolumn{6}{|l|}{ First trimester } \\
\hline HBAlc at booking (\%) & 7.3 & 7.1 & 7.4 & 6.2 & \\
\hline Mean HBAlc (mmol/mol) & $56.3 \pm 15.2$ & $54.2 \pm 13.6$ & $57.4 \pm 16.0$ & $44.57 \pm 9.4$ & 0.040 \\
\hline Booking $<43 \mathrm{mmol} / \mathrm{mol}(6.1 \%)$ & $16.9 \%$ & $17.5 \%$ & $16.6 \%$ & $52.2 \%$ & 0.000 \\
\hline \multicolumn{6}{|l|}{ Yes $(n=42)$} \\
\hline \multicolumn{6}{|l|}{ Second trimester } \\
\hline HBAlc (\%) & 6.0 & 5.9 & 6.1 & 5.4 & \\
\hline Mean HBAlc $(\mathrm{mmol} / \mathrm{mol})$ & $42.43 \pm 8.9$ & $40.7 \pm 8.1$ & $43.2 \pm 9.2$ & $35.11 \pm 5.8$ & 0.005 \\
\hline \multicolumn{6}{|l|}{ Third trimester } \\
\hline HBAlc (\%) & 6.2 & 6.2 & 6.3 & 5.6 & \\
\hline Mean HBAlc (mmol/mol) & $44.22 \pm 8.0$ & $43.0 \pm 8.0$ & $45.0 \pm 8.0$ & $37.53 \pm 6.4$ & 0.002 \\
\hline
\end{tabular}

Data are presented as mean \pm standard deviation $(\mathrm{SD})$ or $\%$

HBAlc Haemoglobin Alc

and more congenital malformations (10\% vs. $2.3 \%)$. The intrauteral foetal death rate was marginally higher among CSII patients $(2.5 \%$ vs. $2.3 \%, p=0.05)$. The admission rate in NICU was higher in infants of the MDI group (54\%), but the rate of neonatal hypoglycaemia was similar in both groups (31\%). Pre-eclampsia and pregnancy-induced hypertension were similar in both groups ( $9 \%$ vs. $11.2 \%$ and $20 \%$ vs. $22 \%$ ).

\section{DISCUSSION}

In this observational retrospective analysis, we studied baseline characteristics, diabetes-related complications, comorbidities, pregnancy and foetal outcomes in patients with pre-pregnancy diabetes mellitus. Our cohort with T2DM were of wide ethnic diversity with $41 \%$ being of nonEuropean descent, whereas, the majority of our T1DM cohort were of European origin (96\%). Women with T2DM were overweight, older, had lower attendance to pre-pregnancy service and presented at booking visit at a greater gestational age. On the other hand, women with T1DM had a longer duration of the disease, more diabetic retinopathy, hypothyroidism, a higher risk for developing pre-eclampsia and higher rates of pregnancy-induced hypertension. Both of our cohorts showed good adherence to high-dose folic acid prior to conception. Moreover, we found that pregnant women with T2DM and T1DM started their pregnancies with different glycaemic control levels; T1DM women had a better improvement in HbA1c throughout pregnancy than their T2DM counterparts. In further analysis of glycaemic control, women with type 2 diabetes mellitus had a better HbA1c at their booking visit and throughout the pregnancy compared with T1DM patients who had suboptimal glycaemic control at booking with subsequent improvement throughout the pregnancy.

It is established that diabetes mellitus care during the pre-pregnancy period is one of the most important factors leading to better glycaemic control and favourable obstetrical outcomes in pregnant women with diabetes mellitus[7].Improvement in glycaemic control during pregnancy decreased the risk of LGA infants [18-20], preterm delivery [21] and preeclampsia [22] in previous studies. We found 
Table 4 Maternal, obstetric and foetal characteristics of type 1 diabetes patients

\begin{tabular}{|c|c|c|c|c|}
\hline Mean \pm SD & $\begin{array}{l}\text { All type } 1 \text { diabetes } \\
n=124\end{array}$ & $\begin{array}{l}\text { CSII } \\
n=40 \text { (32) }\end{array}$ & $\begin{array}{l}\text { MDI } \\
n=84(67)\end{array}$ & $P$ value \\
\hline Age (years) & $33.8 \pm 4.7$ & $34.3 \pm 4.0$ & $33.5 \pm 5.0$ & 0.524 \\
\hline Booking BMI (kg/m²) & $26.3 \pm 4.5$ & $26.6 \pm 4.7$ & $26.2 \pm 4.4$ & 0.296 \\
\hline Duration of diabetes (years) & $15.7 \pm 8.0$ & $18.5 \pm 8.3$ & $14.3 \pm 7.6$ & 0.015 \\
\hline Booking gestational age (weeks) & $6.0 \pm 1.7$ & $5.3 \pm .93$ & $6.6 \pm 2.0$ & 0.024 \\
\hline Birth weight (kg) & $3.63 \pm 0.76$ & $3.75 \pm 0.71$ & $3.58 \pm 0.78$ & 0.306 \\
\hline \multicolumn{5}{|l|}{ Percentage (\%) } \\
\hline European origin & 96.0 & 100 & 94.0 & 0.130 \\
\hline \multicolumn{5}{|l|}{ Yes $(n=120)$} \\
\hline Primiparous & 44.4 & 52.5 & 40.2 & 0.207 \\
\hline \multicolumn{5}{|l|}{ Yes $(n=52)$} \\
\hline $\begin{array}{l}\text { Pre-conception clinic attendee } \\
\text { Yes }(n=49)\end{array}$ & 62.0 & 66.6 & 59.6 & 0.538 \\
\hline $\begin{array}{l}\text { Preconception folic acid ( } 5 \mathrm{mg}) \\
\text { Yes }(n=44)\end{array}$ & 70.5 & 74.0 & 68.6 & 0.614 \\
\hline $\begin{array}{l}\text { Hypothyroidism } \\
\text { Yes }(n=26)\end{array}$ & 21.0 & 33.3 & 15.4 & 0.070 \\
\hline \multicolumn{5}{|l|}{ Diabetes complications } \\
\hline \multicolumn{5}{|l|}{ Yes $(n=29)$} \\
\hline \multicolumn{5}{|l|}{ Mode of delivery } \\
\hline $\begin{array}{l}\text { Spontaneous vaginal delivery } \\
\text { Yes }(n=27)\end{array}$ & 21.6 & 15.0 & 25.0 & 0.339 \\
\hline \multicolumn{4}{|l|}{ Yes $(n=20)$} & 0.623 \\
\hline \multicolumn{4}{|l|}{ Yes $(n=40)$} & 0.194 \\
\hline $\begin{array}{l}\text { Assisted normal delivery } \\
\text { Yes }(n=9)\end{array}$ & 7.2 & 7.5 & 7.1 & 0.925 \\
\hline
\end{tabular}


Table 4 continued

\begin{tabular}{|c|c|c|c|c|}
\hline Mean \pm SD & $\begin{array}{l}\text { All type } 1 \text { diabetes } \\
n=124\end{array}$ & $\begin{array}{l}\text { CSII } \\
n=40(32)\end{array}$ & $\begin{array}{l}\text { MDI } \\
n=84(67)\end{array}$ & $P$ value \\
\hline $\begin{array}{l}\text { Miscarriage } \\
\text { Yes }(n=26)\end{array}$ & 20.8 & 25.0 & 19.0 & 0.596 \\
\hline $\begin{array}{l}\text { Intrauterine foetal death } \\
\text { Yes }(n=3)\end{array}$ & 2.4 & 2.5 & 2.3 & 0.050 \\
\hline $\begin{array}{l}\text { Live births } \\
\text { Yes }(n=95)\end{array}$ & 76.0 & 70.0 & 78.5 & 0.447 \\
\hline Foetal complications & & & & \\
\hline $\begin{array}{l}\text { Postnatal hypoglycaemia } \\
\text { Yes }(n=21)\end{array}$ & 31.3 & 31.8 & 31.8 & 0.684 \\
\hline $\begin{array}{l}\text { NICU admission } \\
\text { Yes }(n=35)\end{array}$ & 52.2 & 45.4 & 54.5 & 0.407 \\
\hline $\begin{array}{l}\text { Abdominal circumference }>95 \text { th } \\
\text { Yes }(n=20)\end{array}$ & 23.8 & 25.0 & 23.3 & 0.026 \\
\hline $\begin{array}{l}\text { Birth weight }>4.5 \mathrm{~kg} \text { (LGA) } \\
\text { Yes }(n=7)\end{array}$ & 7.2 & 13.7 & 4.4 & 0.284 \\
\hline $\begin{array}{l}\text { Birth weight }>4.0 \mathrm{~kg} \\
\text { Yes }(n=20)\end{array}$ & 20.6 & 17.2 & 22.3 & 0.671 \\
\hline $\begin{array}{l}\text { Congenital anomalies } \\
\text { Yes }(n=6)\end{array}$ & 4.8 & 10.0 & 2.3 & 0.198 \\
\hline $\begin{array}{l}\text { Postnatal hypoglycaemia } \\
\text { Yes }(n=21)\end{array}$ & 31.3 & 31.8 & 31.8 & 0.684 \\
\hline $\begin{array}{l}\text { Pre-eclampsia } \\
\text { Yes }(n=11)\end{array}$ & 10.6 & 9.0 & 11.2 & 0.116 \\
\hline $\begin{array}{l}\text { Pregnancy-induced hypertension } \\
\text { Yes }(n=21)\end{array}$ & 21.4 & 20.0 & 22.0 & 0.523 \\
\hline
\end{tabular}

Data are presented as mean \pm standard deviation $(\mathrm{SD})$ or $\%$

Bold indicates the significant values $(p<0.05)$

$B M I$ body mass index, $M D I$ multiple daily injections, CSII continuous subcutaneous insulin infusion, NICU neonatal intensive care unit, $C S$ caesarean section

that insulin pump users and MDI users with T1DM started pregnancy with similar glycaemic control levels; however, SCII users had lower HbA1c throughout pregnancy. This has been reported in a number of previous studies [23-27]; the opposite finding was seen in one recent trial using continuous glucose monitoring [28]. In one study, SCII patients had higher 
rates of miscarriage and emergency CS and a marginally raised rate of IUFD and congenital anomalies; their babies were heavier and had a higher rate of LGA. These findings were explained by the possibility of the effect of gestational weight gain in CSII users compared to MDI users [29]. Our study showed similar foetal and maternal outcomes. The majority of our SCII users were commenced on the treatment before pregnancy. There was no difference in neonatal hypoglycaemia between SCII and MDI users. We found no statistically significant differences in glycaemic control in the second and third trimester between the groups, and both achieved the pregnancy target of HbA1c $\leq$ $48 \mathrm{mmol} / \mathrm{mol} 6.5 \%$. A study by Murphy et al. on glucose disposal and plasma insulin concentration in T1DM during pregnancy found significant delays in postprandial glucose disposal during late gestation in SCII users [30]. This is likely to result in prolonged postprandial hyperglycemia in late pregnancy and impact the overall glycaemic control. In our study SCII users achieved similar glycaemic control during late pregnancy compared to MDI users. Offspring of women on MDI treatment had higher rates of NICU admissions in our study, different from the finding observed in the CONCEPTT trial [28]. In one study of T1DM-complicated pregnancy, CSII compared to MDI therapy resulted in better first trimester glycaemic control; this difference decreased in subsequent trimesters. CSII therapy was associated with lower insulin requirements, higher GWG and altered risk for infants being LGA and SGA [31]. MDI and CSII are both effective approaches in pregnancy. However, if CSII is to be initiated, it should be started well before conception to allow women time to acclimate to the pump and ensure tight diabetes control before pregnancy, and all supporting staff should be comfortable using this treatment.

Strengths of our study include a large number of patients with pre-existing diabetes, especially type 1 diabetes mellitus, with a large proportion of patients using CSII therapy throughout the pregnancy. Our patients were treated with a multidisciplinary team consisting of endocrinologists, obstetricians, diabetes specialised midwives, dietitians, an ophthalmologist and psychologists. All patients received diabetes self-management education with instructions to optimise insulin adjustment. We used self-blood glucose monitoring with glucose targets recommended by the NICE guideline [32]. However, a weakness of this study is its retrospective analysis, and women attending our service had pre-pregnancy attendance in their general diabetes centres outside our institution. We do not have accurate data on total daily doses of insulin as nearly all of our women used insulin with meals calculating from the individual insulin to carbohydrate ratio.

\section{CONCLUSIONS}

Women in our study with pre-gestational diabetes were overweight, were older and had longstanding diabetes mellitus. Our patients with type 2 diabetes were older, had a higher BMI, had a shorter duration of diabetes mellitus and had better diabetes control compared to women with type 1 diabetes. Women treated with continuous subcutaneous insulin infusion had a higher rate of miscarriage with more congenital malformations. The initial inadequate diabetes control was significantly improved during pregnancy. With an appropriate multidisciplinary team approach, we minimised adverse outcomes and identified areas for improvement in delivery of care in the future.

\section{ACKNOWLEDGEMENTS}

Funding. No funding or sponsorship was received for this study or publication of this article.

Authorship. All named authors meet the International Committee of Medical Journal Editors (ICMJE) criteria for authorship for this article, take responsibility for the integrity of the work as a whole, and have given their approval for this version to be published. 
Authorship Contributions. D.S.A and R.D. performed analysis and interpretation of the data and drafted the manuscript. E.R., C.C. and H.D. collected the data and participated in patient's care. J.W, M.H. and M.H. were responsible for patient's care and the design of this study. M.H is the guarantor of this work and, as such, had full access to all the data in the study and takes responsibility for the integrity of the data and the accuracy of the data analysis.

Prior Presentation. This submission was previously presented at the American Diabetes Association $2019 \quad$ (https://diabetes. diabetesjournals.org/content/68/Supplement_ 1/200-LB).

Disclosures. Dalal S Ali, Recie Davern, Eimear Rutter, Ciara Coveney, Hilary Devine, Jennifer M. Walsh, Mary Higgins and Mensud Hatunic have nothing to disclose.

Compliance with Ethics Guidelines. The data collection for this study was approved by the Research Ethics Committee National Maternity Hospital, Holles Street, Dublin, Ireland.

Data Availability. The datasets generated and analysed during the study are not publicly available due European GDPR law.

Open Access. This article is licensed under a Creative Commons Attribution-NonCommercial 4.0 International License, which permits any non-commercial use, sharing, adaptation, distribution and reproduction in any medium or format, as long as you give appropriate credit to the original author(s) and the source, provide a link to the Creative Commons licence, and indicate if changes were made. The images or other third party material in this article are included in the article's Creative Commons licence, unless indicated otherwise in a credit line to the material. If material is not included in the article's Creative Commons licence and your intended use is not permitted by statutory regulation or exceeds the permitted use, you will need to obtain permission directly from the copyright holder. To view a copy of this licence, visit http://creativecommons.org/licenses/by$\mathrm{nc} / 4.0 /$.

\section{REFERENCES}

1. Tennant PW, Glinianaia SV, Bilous RW, Rankin J, Bell R. Pre-existing diabetes, maternal glycated haemoglobin, and the risks of fetal and infant death: a population-based study. Diabetologia. 2014;57(2):285-94.

2. Vambergue A, Fajardy I. Consequences of gestational and pregestational diabetes on placental function and birth weight. World J Diabetes. 2011;2(11):196-203.

3. Murphy HR, Bell R, Cartwright C, Curnow P, Maresh M, Morgan M, Lewis-Barned N. Improved pregnancy outcomes in women with type 1 and type 2 diabetes but substantial clinic-to-clinic variations: a prospective nationwide study. Diabetologia. 2017;60(9):1668-777.

4. Mackin ST, Nelson SM, Kerssens JJ, Wood R, Wild S, Colhoun HM, Leese GP, Philip S, Lindsay RS. Diabetes and pregnancy: national trends over a 15 year period. Diabetologia. 2018;61(5):1081-8.

5. Macintosh MC, Fleming KM, Bailey JA, Doyle P, Modder J, Acolet D, Golighty S, Miller A. Perinatal mortality and congenital anomalies in babies of women with type 1 or type 2 diabetesin England, Wales, and Northern Ireland: population based study. BMJ. 2006;333(7560):177-83.

6. Egan AM, Brassill MJ, Brosnan E, Carmody L, Clarke H, Coogan Kelly C, Culliney L, Durkan M, Fenlon M, Ferry P, Hanlon G. An Irish National Diabetes in pregnancy audit: aiming for best outcomes for women with diabetes. Diabet Med. 2019. https:// doi.org/10.1111/dme.13923.

7. Wahabi HA, Alzeidan RA, Bawazeer GA, Alansari LA, Esmaeil SA. Preconception care for diabetic women for improving maternal and fetal outcomes: a systematic review and meta-analysis. BMC Pregnancy Childbirth. 2010;10(1):63-77.

8. McElvy SS, Miodovnik M, Rosenn B, Khoury JC, Siddiqi T, Dignan PSJ, Tsang RC. A focused pre conceptional and early pregnancy program in women with type 1 diabetes reduces perinatal mortality and malformation rates to general population levels. J Matern-Fetal Med. 2000;9(1):14-20.

9. Confidential Enquiry into Maternal and Child Health (CEMACH) Diabetes in pregnancy: are we 
providing the best care? Findings of a national enquiry 2007. http://www.hqip.org.uk/assets/ NCAPOP-Library/CMACE-Reports/25.-February2007. Accessed 21 Sept 2019.

10. Evers IM, de Valk HW, Visser GH. Risk of complications of pregnancy in women with type 1 diabetes: nationwide prospective study in the Netherlands. BMJ. 2004;328(7445):915-20.

11. Persson M, Norman M, Hanson U. Obstetric and perinatal outcomes in type 1 diabetic pregnancies: a large, population-based study. Diabetes Care. 2009;32(11):2005-9.

12. The Saint Vincent Declaration. Acta Ophthalmol Scand. 1997; 75:63.

13. DeSilva M, Munoz FM, Mcmillan M, Kawai AT, Marshall H, Macartney KK, Joshi J, Oneko M, Rose AE, Dolk H, Trotta F. Congenital anomalies: case definition and guidelines for data collection, analysis, and presentation of immunization safety data. Vaccine. 2016;34(49):6015-26.

14. Guerin A, Nisenbaum R, Ray JG. Use of maternal $\mathrm{GHb}$ concentration to estimate the risk of congenital anomalies in the offspring of women with prepregnancy diabetes. Diabetes Care. 2007;30(7): 1920-5.

15. Jensen DM, Korsholm L, Ovesen P, Beck-Nielsen H, Moelsted-Pedersen L, Westergaard JG, Moeller M, Damm P. Peri-conceptional A1C and risk of serious adverse pregnancy outcome in 933 women with type 1 diabetes. Diabetes Care. 2009;32(6):1046-8.

16. Nielsen GL, Møller M, Sørensen HT. HbA1c in early diabetic pregnancy and pregnancy outcomes: a Danish population-based cohort study of 573 pregnancies in women with type 1 diabetes. Diabetes Care. 2006;29(12):2612-6.

17. Suhonen L, Hiilesmaa V, Teramo K. Glycaemic control during early pregnancy and fetal malformations in women with type I diabetes mellitus. Diabetologia. 2000;43(1):79-82.

18. Holmes VA, Young IS, Maresh MJA, Pearson DWM, Walker JD, McCance DR, DAPIT Study Group. The diabetes and pre-eclampsia intervention trial. Int J Gynecol Obstetr. 2004;87(1):66-71.

19. Hummel M, Marienfeld S, Huppmann M, Knopff A, Voigt M, Bonifacio E, Ziegler AG. Fetal growth is increased by maternal type 1 diabetes and HLA DR4-related gene interactions. Diabetologia. 2007;50(4):850-8.

20. Cyganek K, Skupien J, Katra B, Hebda-Szydlo A, Janas I, Trznadel-Morawska I, Witek P, Kozek E, Malecki MT. Risk of macrosomia remains glucose- dependent in a cohort of women with pregestational type 1 diabetes and good glycemic control. Endocrine. 2017;55(2):447-55.

21. Abell SK, Boyle JA, de Courten B, Soldatos G, Wallace EM, Zoungas S, Teede HJ. Impact of type 2 diabetes, obesity and glycaemic control on pregnancy outcomes. Aust N Z J Obstet Gynaecol. 2017;57(3):308-14.

22. Temple RC, Aldridge V, Stanley K, Murphy HR. Glycaemic control throughout pregnancy and risk of pre-eclampsia in women with type I diabetes. BJOG. 2006;113(11):1329-32.

23. Pickup JC, Sutton AJ. Severe hypoglycaemia and glycaemic control in Type1 diabetes: meta-analysis of multiple daily insulin injections compared with continuous subcutaneous insulin infusion. Diabet Med. 2008;25:765-74. https://doi.org/10.1111/j. 1464-5491.2008.02486.x.

24. Jeitler K, Horvath K, Berghold A, Gratzer TW, Neeser K, Pieber TR, Siebenhofer A. Continuous subcutaneous insulin infusion versus multiple daily insulin injections in patients with diabetes mellitus: systematic review and meta-analysis. Diabetologia. 2008;51:941-51. https://doi.org/10.1007/s00124008-0974-3.

25. Giménez M, Conget I, Jansà M, Vidal M, Chiganer G, Levy I. Efficacy of continuous subcutaneous insulin infusion in Type 1 diabetes: a 2 -year perspective using the established criteria for funding from a National Health Service. Diabet Med. 2007;24:1419-23. https://doi.org/10.1111/j.14645491.2007.02287.x.

26. Janez A. Continuous subcutaneous insulin infusion in adult type 1 diabetes mellitus: data from a registry at the University Medical Centre Ljubljana Slovenia, J Int Med Res. 2012;40:1546-51. https:// doi.org/10.1177/147323001204000434.

27. Jankovec Z, Hahn M, Grunder S, Lacigova S, Cechurova D, Krcma M, Zourek M, Haladova I, Rusavy Z. Analysis of continuous patient data from the Czech National Register of patients with type 1 and type 2 diabetesu sing insulin pump therapy. Diabetes Res Clin Pract. 2010;87:219-23. https:// doi.org/10.1016/j.diabres.2009.09.028.

28. Feig DS, Corcoy R, Donovan LE, Murphy KE, Barrett JF, Sanchez JJ, Wysocki T, Ruedy K, Kollman C, Tomlinson G, Murphy HR. Pumps or multiple daily injections in pregnancy involving type 1 diabetes: a prespecified analysis of the CONCEPTT randomized trial. Diabetes Care. 2018;41(12):2471-9.

29. Cyganek K, Skupien J, Katra B, Hebda-Szydlo A, Janas I, Trznadel-Morawska I, Witek P, Kozek E, Malecki MT. Risk of macrosomia remains glucose- 
dependent in a cohort of women with pregestational type 1 diabetes and good glycemic control. Endocrine. 2017;55:447-55. https://doi.org/10. 1007/s12020-016-1134-z.

30. Murphy HR, Elleri D, Allen JM, et al. Pathophysiology of postprandial hyperglycaemia in women with type 1 diabetes during pregnancy. Diabetologia. 2012;55:282-93.

31. Rys PM, Ludwig-Slomczynska AH, Cyganek K, Malecki MT. Continuous subcutaneous insulin infusion vs multiple daily injections in pregnant women with type 1 diabetes mellitus: a systematic review and meta-analysis of randomised controlled trials and observational studies. Eur J Endocrinol. 2018;178(5):545-63. https://doi.org/10.1530/EJE$17-0804$.

32. National Institute for Health and Clinical Excellence. Diabetes in Pregnancy. Management of diabetes and its complications in pregnancy from the pre-conception to the postnatal period. NICE Guideline 63. 2008. www.nice.org.uk. Accessed 2015. 